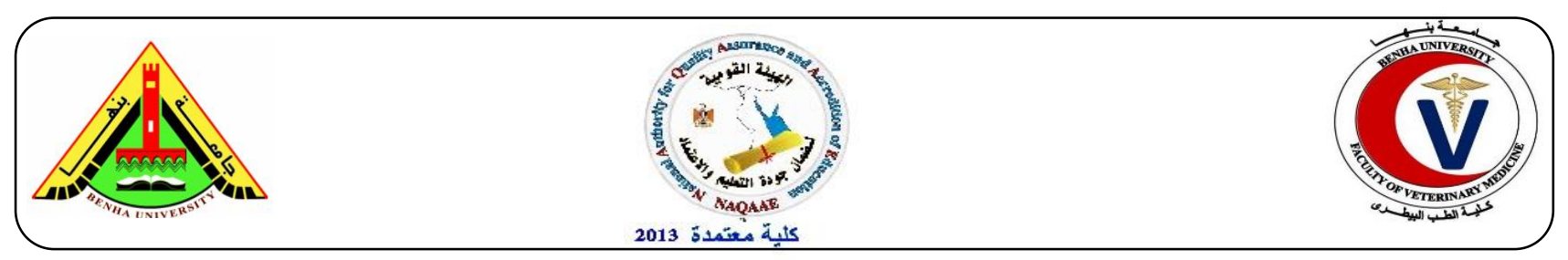

\title{
Rancidity as Lipolytic Index in Poultry Meat Cuts
}

Faten, S. Hassanin ${ }^{1}$; Hassan M.A. ${ }^{1}$; Nabila, I. Elsheikh ${ }^{2}$; Tereza, H. Amin ${ }^{2}$

1 Food Control Department. Faculty of Veterinary Medicine, Benha University

2 Animal Health Research Institute, Tanta Gharbia

\section{A B S T R A C T}

Ninety random samples of fresh poultry meat cuts represented by chicken thigh \& breast, duck thigh \& breast and turkey thigh \& breast (15 of each) were collected from different slaughtered shops Tanta city, Gharbia government. The collected samples were analyzed for determination of thiobarbiturc acid (TBA), perioxide value (P.V.) free fatty acids (FFAs) and fractionation of fatty acids to determine their lipolytic indices for their keeping quality as well as their composition of fatty acids. The obtained results showed that mean values for duck thigh, chicken thigh and turkey thigh samples were $0.52 \pm 0.03,0.33 \pm 0.02$ and $0.15 \pm 0.01(\mathrm{mg} / \mathrm{kg})$ for TBA \& $0.85 \pm 0.09,0.57 \pm 0.07$ and $0.33 \pm 0.04\left(\mathrm{mgO}_{2} / \mathrm{kg}\right)$ for PV, respectively. Plus, $0.69 \pm 0.07,0.45 \pm 0.06$ and $0.28 \pm 0.02(\mathrm{mg} \%)$ for FFAs, respectively. Concerning breast of both duck, chicken and turkey samples, the mean values were $0.40 \pm 0.02,0.19 \pm 0.01$ and $0.12 \pm 0.01(\mathrm{mg} / \mathrm{kg})$ for TBA, where, $0.64 \pm 0.07,0.41 \pm 0.05$ and $0.27 \pm 0.02\left(\mathrm{mgO}_{2} / \mathrm{kg}\right)$ for PV. As well as, $0.52 \pm 0.05,0.36 \pm 0.03$ and $0.20 \pm 0.03(\mathrm{mg} \%)$ for FFAs respectively. Finally, samples subjected to fractionation of fatty acids the ratio between total unsaturated fatty acids and total saturated fatty acids were $0.96,1.23$ and 1.66 for thigh of duck, chicken and turkey, respectively. While breast of duck, chicken and turkey ratios were 1.15, 1.45 and 2.23 respectively. Turkey breast meat had the highest keeping quality and nutritive value compared with the other samples.

Keywords: TBA, PV, FFA, Poultry

(http://www.bvmj.bu.edu.eg)(BVMJ-33(2): 343-350, 2017)

\section{INTRODUCTION}

In Egypt, chickens occupy large scale in production and consumption among poultry. Chicken meat becomes the second most popular meat eaten and is considered as a good source of protein and nutrients and is relatively low in fat, especially when skin is removed. Chicken meat is also characterized by ease of preparation, consistent quality and the availability of a wide range of pre-packed, branded, raw and ready to eat and serve products (Shedeed, 1999).
Being a white meat, chicken meat is more superior to red meat due to several reasons, including its health benefits, as it contains less fat and cholesterol, easy to handle portion (Liu et al., 2012).

The meat is an important sources of fat in typical diets in the world, many consumers believe that red meat is unhealthful, due to high saturated fatty acids (SFA) and cholesterol. Recently, it has been demonstrated that replacement of red meat 
with chicken is associated with significant decrease in a polypoprotein B and total cholesterol levels in microalbumin uric type 2 diabetic patients this effect is probably related to the higher PUFA (polyunsaturated fatty acids) content of chicken meat in comparison to beef (Gross et al., 2002).

The microbial activities are considered the major factor of foods alteration during storage and manipulation, when these activities are under efficient control, the foods alteration will be of chemical nature, lipid oxidation is a principal chemical changes of foods, which depends on the level of oxygen and metals. Lipid oxidation products are responsible for the development of rancidity by the production of low molecular weight compounds that cause undesirable flavor (Frankel et al., 1987).

Cholesterol is also oxidized in similar reaction mechanisms to those observed of fatty acids. Many of the cholesterol oxidation products have adverse effect such as cytotoxicity and modifications of enzyme activity (Bosinger et al., 1993) atherosclerosis (Kumar and Singal, 1991) carcinogenicity and mutagenicity (Ansari and Smith, 1979).

Oxidative deterioration results in losing the quality of poultry meat due to development of rancid odor and taste. Moreover, the rancid flavor can develop rapidly during refrigerated storage of such frozen poultry meats, which are more susceptible to rancidity because of their high contents of unsaturated fatty acid (Ang, 1988).

The thiobarbituric acid (TBA) method is the most widely used test for measuring the extent of lipid peroxidation in red meat and poultry, due to its speed and simplicity (Raharjo and Sofos, 1993).

Therefore, the aim of this present study was to evaluate the lipolytic indices for keeping quality and fat composition for nutrition value of poultry meat.

\section{Materials and methods}

\subsection{Collection of samples:}

Ninety random samples of fresh poultry meats represented by chicken thigh \& breast, duck thigh $\&$ breast and turkey thigh $\&$ breast (15 of each) were collected from different slaughtered poultry shops in Tanta city, Gharbia government. All collected samples were kept in a separated sterile plastic bag and preserved in an ice box then transferred as quickly as possible to the laboratory with a minimum limit of delay and then subjected to following examination.

\subsection{Determination of Thiobarbituric Acid} Number (TBA) Pikul et al. (1989):

2.3. Determination of Peroxide value (Asakawa and Matsushita, 1978):

2.4. Determination of Free Fatty Acids (FFA):

2.4.1. Lipid Extraction Using the Folch Method (Folch et al., 1957):

\subsubsection{Titration procedure (Brake and Fennema, 1999):}

2.5. Fractionation of fatty acids:

\subsubsection{Extraction of fat from chicken meat:}

One hundred grams of the sample were placed in a $500 \mathrm{ml}$ closed stopper flask then, $300 \mathrm{ml}$ of $\mathrm{n}$-hexane were added, and the flask was shacked for $30 \mathrm{~min}$. using horizontal shaker and left for 24 hours at room temperature. The homogenated mixture was filtered and the residue was re-extracted as mentioned above. The combined filtrates were evaporated under reduced pressure, according to AOAC, (2000).

2.5.2. Identification and determination of fatty acids:

Fatty acids were determined in meat by Gas Chromatography technique (GC) according to Aura et al. (1995).

\subsubsection{Isolation and extraction of fatty acids:}

The fats under study were saponified with ethanolic potassium hydroxide $(40 \%, \mathrm{w} / \mathrm{v})$ for 
24 hours at room temperature according to the method of AOCS (1993).

The aqueous layer (containing potassium salt of fatty acids and free from unsaponifiable matter) was acidified with HCL $(0.5 \mathrm{~N})$, and then it was extracted three times with petroleum ether. The petroleum ether extract was washed several times with distilled water, and dried over anhydrous sodium sulphate.

2.5.4. Methylation of fatty acids (Vogel, 1975):

\subsubsection{Separation of fatty acid methyl esters:}

The fatty acids methyl esters were analyzed by Hewlett Packard gas chromatography (5890 series) equipped with flame ionization detector. The chromatograph was fitted with FFAP $(2.5 \mathrm{~m} \times 0.30 \mu \mathrm{m}$ film thickness and $0.32 \mathrm{~mm}$ diameter).

Capillary column coated with polyethylene glycol. The column oven temperature was programmed from $50^{\circ} \mathrm{C}$ to $240^{\circ} \mathrm{C}\left(7^{\circ} \mathrm{C} / \mathrm{min}\right.$. $)$ and finally kept at $240^{\circ} \mathrm{C}$ for 30 minutes. Injector and detector temperature were 250 and $260^{\circ} \mathrm{C}$, respectively. Gases flow rates were 33,30 and $330 \mathrm{ml} / \mathrm{min}$. for $\mathrm{N} 2, \mathrm{H} 2$ and air, respectively.

The flow rate inside column was $2 \mathrm{ml} / \mathrm{min}$. Under these conditions, all peaks from $\mathrm{C} 8$ to C22 homologous series well defined. Peak identification was performed by comparison of the relative retention time (RTT) for each peak with those of standard chromatograms. The peak was measured by triangulation and the relative proportions of the individual compound were therefore obtained by determination of the partial areas in relation to the total area.

\section{RESULTS}

From achieved results in table (1) it is showed that mean values of TBA "mg/ $/ \mathrm{kg}$ " in examined thigh samples were $0.52 \pm 0.03$ for duck samples, $0.33 \pm 0.02$ for chicken samples and $0.15 \pm 0.01$ for turkey samples.
Concerning breast sample, the mean value of TBA were $0.40 \pm 0.02,0.019 \pm 0.01$ and $0.12 \pm 0.01$ for duck, chicken and turkey, respectively.

The data recorded in table (2) declared that perioxide mean values were $0.85 \pm 0.09$, $0.57 \pm 0.08$ and $0.33 \pm 0.04$ for duck, chicken and turkey thigh samples, respectively. While breast sample mean values were $0.64 \pm 0.07$, $0.11 \pm 0.05$ and $0.27 \pm 0.02$ for duck, chicken and turkey, respectively.

It is evident from results obtained in table (3) that free fatty acids mean values were $0.69 \pm 0.07, \quad 0.45 \pm 0.04$ and $0.28 \pm 0.02$.For duck, chicken and turkey thigh samples, respectively. On the other hand breast samples mean values were $0.52 \pm 0.05$, $0.36 \pm 0.03$ and $0.20 \pm 0.03$ for duck, chicken and turkey, respectively.

It is obvious from results obtained in table (4) that total saturated fatty acids (TSFAs) were $2481 \& 2253$; Total mono unsaturated fatty acids (TMUFAs) were $1660 \& 1741$. Plus, total poly unsaturated fatty acids (TPUFAs) were $745 \& 869$ in thigh and breast of duck samples respectively. Ratio between total unsaturated FAs and total saturated FAs was 0.969 for thigh samples and 1.15 for breast samples.

Concerning results in table (4), total saturated fatty acids (TSFAs) were 2164 \& 1959 , total mono table unsaturated fatty acids (TMUFAs) were $1793 \& 1872$ and total poly unsaturated fatty acids (TPUFAs) were 884,967 . For thigh and breast of chicken samples, respectively. Ratio between total unsaturated fatty acids to total saturated fatty acids was 1.23 .for thigh samples and 1.45 for breast samples.

Also, in table (4) the results achieved in thigh and breast of turkey samples of total saturated fatty acids, total mono unsaturated fatty acid and total poly unsaturated fatty acid were $1754 \& 1408,1885 \& 2012$ and 1028 \& 1136, respectively. Ratio between total 
unsaturated fatty acids to total saturated fatty

breast samples. acids was 1.66 for thigh samples and 2.23 for

Table (1): Statistical analytical results of Thiobarbituric acid value (TBA) "mg/Kg" in the examined samples of thigh and breast of various poultry meats $(n=15)$.

\begin{tabular}{|c|c|c|c|c|c|c|}
\hline Cuts & Thigl & & & Breas & & \\
\hline Species & Min & Max & Mean \pm S.E ${ }^{*}$ & Min & Max & Mean \pm S.E \\
\hline Duck & 0.36 & 0.64 & $0.52 \pm 0.03$ & 0.29 & 0.51 & $0.40 \pm 0.02$ \\
\hline Chicken & 0.18 & 0.39 & $0.33 \pm 0.02$ & 0.11 & 0.25 & $0.19 \pm 0.01$ \\
\hline Turkey & 0.07 & 0.21 & $0.15 \pm 0.01$ & 0.06 & 0.19 & $0.12 \pm 0.01$ \\
\hline
\end{tabular}

Table (2): Statistical analytical results of Peroxide value (PV) "meqO2/kg" in the examined samples of thigh and breast of various poultry meats $(n=15)$.

\begin{tabular}{lllllll}
\hline \multicolumn{1}{c}{ Cuts } & \multicolumn{5}{c}{ Thigh } & \multicolumn{3}{c}{ Breast } \\
\cline { 2 - 7 } Species & Min & Max & Mean \pm S.E & Min & Max & Mean \pm S.E $^{*}$ \\
\hline Duck & 0.68 & 1.03 & $0.85 \pm 0.09$ & 0.47 & 0.83 & $0.64 \pm 0.07$ \\
Chicken & 0.35 & 0.76 & $0.57 \pm 0.08$ & 0.23 & 0.58 & $0.41 \pm 0.05$ \\
Turkey & 0.21 & 0.53 & $0.33 \pm 0.04$ & 0.16 & 0.44 & $0.27 \pm 0.02$ \\
\hline
\end{tabular}
S.E ${ }^{*}=$ standard error of mean
High significant differences $(\mathrm{P}<0.01)$

Table (3): Statistical analytical results of free fatty acids ( $\mathrm{mg} \%)$ in the examined samples of thigh and breast of various poultry meats $(n=15)$.

\begin{tabular}{lllllll}
\hline \multicolumn{1}{c}{ Cuts } & \multicolumn{5}{c}{ Thigh } & \multicolumn{3}{c}{ Breast } \\
\cline { 2 - 7 } & Min & Max & Mean \pm S.E & Min & Max & Mean \pm S.E \\
\hline Duck & 0.49 & 0.87 & $0.69 \pm 0.07$ & 0.45 & 0.71 & $0.52 \pm 0.05$ \\
Chicken & 0.30 & 0.64 & $0.45 \pm 0.06$ & 0.21 & 0.48 & $0.36 \pm 0.03$ \\
Turkey & 0.19 & 0.36 & $0.28 \pm 0.02$ & 0.15 & 0.32 & $0.20 \pm 0.03$ \\
\hline
\end{tabular}


Table (4): Fractionation of fatty acid composition ( $\mathrm{mg} / 100 \mathrm{~g})$ in the examined samples of duck, chicken and turkey meat cuts.

\begin{tabular}{|c|c|c|c|c|c|c|}
\hline \multirow{2}{*}{ Fatty acids } & \multicolumn{2}{|c|}{ Duck meat } & \multicolumn{2}{|c|}{ Chicken } & \multicolumn{2}{|c|}{ Turkey } \\
\hline & Thigh & Breast & Thigh & Breast & Thigh & Breast \\
\hline Lauric acid (C12:0) & 59 & 42 & 41 & 29 & 30 & 21 \\
\hline Myristic (C14:0) & 106 & 95 & 95 & 63 & 48 & 34 \\
\hline Palmitic (C16:0) & 1582 & 1430 & 1378 & 1291 & 1225 & 1029 \\
\hline Stearic (C18:0) & 734 & 686 & 650 & 576 & 451 & 324 \\
\hline Total Saturated F.As & 2481 & 2253 & 2164 & 1959 & 1754 & 1408 \\
\hline Palmitoleic (C16:1) & 290 & 347 & 356 & 404 & 376 & 455 \\
\hline Oleic (C18:1) & 1370 & 1394 & 1437 & 1468 & 1509 & 1557 \\
\hline Total Mono-Unsaturated F.As & 1660 & 1741 & 1793 & 1872 & 1885 & 2012 \\
\hline Linoleic (C18:2) & 516 & 558 & 597 & 615 & 660 & 718 \\
\hline Linolenic (C18:3) & 74 & 83 & 89 & 97 & 107 & 120 \\
\hline Eicosadienoic acid (C20:2) & 10 & 17 & 14 & 22 & 19 & 26 \\
\hline Dihomo- $\gamma$-linolenic (C20:3) & 16 & 24 & 20 & 25 & 23 & 31 \\
\hline Arachidonic (C20:4) & 92 & 129 & 135 & 141 & 152 & 163 \\
\hline Eicosapentaenoic "EPA" (C20:5) & 11 & 15 & 12 & 18 & 16 & 20 \\
\hline Docosapentaenoic "DPA" (C22:5) & 14 & 26 & 24 & 29 & 27 & 32 \\
\hline Docosahexaenoic "DHA" (C22:6) & 12 & 17 & 19 & 20 & 24 & 26 \\
\hline Total Poly-Unsaturated F.As & 745 & 869 & 884 & 967 & 1028 & 1136 \\
\hline 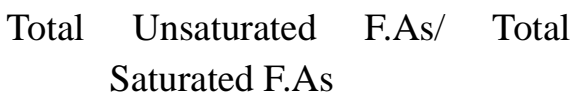 & 0.96 & 1.15 & 1.23 & 1.45 & 1.66 & 2.23 \\
\hline
\end{tabular}

\section{DISCUSSION}

From achieved results in table (1) it is showed that duck meat samples had the highest TBA mean values followed by chicken then turkey which indicate that oxidative rancidity is more in duck followed by chicken then turkey.
High significant differences were associated with the examined samples of poultry species $(\mathrm{P}<0.01)$ and poultry cuts.

Comparing obtained data of chicken thigh and breast samples, it showed that they were in accordance with results of both of AfifiJehan, (2000), lower than Hassanin-Fatin and Hassan, (2003) and higher than Fathy-Eman, (2013).

TBA test has widely used for measuring oxidative rancidity as it is very sensitive for 
evaluating products of unsaturated fatty acids (Melton, 1983).

The data recorded in table (2) declared that peroxide value recorded higher in duck than chicken and turkey indicate faster development of oxidative rancidity.

The obtained results disagreed with Saad et al., (2013) who recorded 0.09 \pm 0.01 , $0.16 \pm 0.01$ and $0.03 \pm 0.01(\mathrm{mg} / \mathrm{kg})$ for TBA and $0.12 \pm 0.01,0.30 \pm 0.01$ and $0.08 \pm 0.01$ for PV for chicken breast, duck breast and pigeon, respectively.

High significant differences $(\mathrm{P}<0.01)$ were obtained as results of poultry species and cuts.

Peroxides values used to determine the quality of fat and it is used as indicator for lipid oxidation (Masoud et al., 2008).

It is evident from results obtained in table (3) that free fatty acids values increased in duck compared with chicken and turkey samples indicating hydrolytic rancidity.

The differences associated with free fatty acid value in examined sample of poultry meat cuts were highly significant $(\mathrm{P}<0.01)$ as results species.

Free fatty acids test used as indicator for hydrolytic rancidity (Melton, 1983).

Hydrolytic rancidity is mainly due to the presence of poly unsaturated fatty acids (Brenner, 2002).

All breast samples have higher keeping quality than thigh samples.

It is evident from results in table (4) that palmatic acid (c16:0) as saturated fatty acid (SFAS) was the highest in duck followed by chicken then turkey meat samples.

On the other hand, turkey has the highest content of oleic acid (C18:1) and linoleic acid (C18:2) as poly unsaturated fatty acids (PUFAS) then chicken and finally duck samples.

The results obtained disagreed with those recorded by (Saad et al., 2013) who recorded the ratio between total unsaturated fatty acid and total saturated fatty acid 0.78, 0.89 and
0.74 for chicken breast, duck breast and whole pigeon, respectively.

The presence of unsaturated fatty acids (UFAS) in food particles increases its nutritive value and contrast, presence of high content of saturated fatty acids (SFAS) lower (decrease) its nutritive value and increase shelf life of the product (Pearson, 1984).

Finally according to the results of examined samples, it is obvious that duck meat has lower nutritive value besides high susceptibility to rancidity (especially thigh samples).

Turkey meat has the highest nutritive value due to high content of PUSFAs and the highest keeping quality as compared with chicken and duck meat samples.

\section{REFERENCES}

Afifi-Jehan, S.A. 2000. Chemical studies on some poultry meat products. M.Sc. Thesis, Vet. Med. ZagazigUniv Egypt.

American Oil Chemists Society "AOCS" 1993.Official Methods and Recommendation Practices of the American Oil Chemists Society. $4^{\text {th }}$ Ed. Published by American Oil Chemists Society, 1608, Broad Moor drive, Champaign, USA.

American Public Health Association "APHA" 1992.Compendium of methods for the microbiological examination of foods. $2^{\text {nd }}$ Ed. Speck, H.L. (ed.).Washington D.C.

Ang, G.Y.W. 1988.Comparison of broiler tissues for oxidative changes after cooking and refrigeration storage. J. Food Sci., 53: 1072-1075.

Ansari, G.A.S. and smith, L.L. 1979.High performance liquid chromatography of cholesterol antioxidation products. J. Chromatography, 175: 307 - 315.

Asakawa, S. and Matsushita, T. 1978.Colorimetric determination of peroxide value with potassium iodide- 
silica gel reagent. J. American Oil

Chemists Society, 55 (8): 619-620.

Association of Official Analytical Chemists "AOAC" 2000.Official Methods and Recommendation Practices of the American Oil Chemists Society. $4^{\text {th }}$ Ed. Published by American Oil Chemists Society, 1608, Broad Moor drive, Champaign, USA.

Bosinger, S.; Luf, W. and Brandi, L. 1993.Oxysterols: Their occurrence and biological effect. Dairy J., 3: 1 - 33.

Brake, N.C. and Fennema, O.R. 1999. Lipolysis and lipid oxidation in frozen minced mackerel as related to molecular diffusion and presence of gelatin. Biochem., 61: 125- 132.

Bremner, A.; Swings, S. and John, D. 2002.Understanding the concepts of quality and freshness in fish. Safety and quality issues in fish processing, 163-172.

Fathy, E. 2012. Chemical analysis of chicken meat with relation to it is quality. Ph.D. Thesis, Fac. Vet. Med. Moshtohor. BenhaUniv Egypt.

Feldman, D.; Ganon, J.; Haffman, R. and Simpson, J. 2003. The solution for data analysis and presentation graphics. $2^{\text {nd }}$ Ed., Abacus Lancripts, Inc., Berkeley, USA.

Folch, J.; Lees, M. and Sloanes, G. 1957.Simple method for the isolation and purification of total lipids from animal tissues. J. Biol. Chem., 226: 497- 509.

Food and Agriculture Organization "FAO" 1980.Manual of Food Quality Control.FAO, United Nation, Rome, Italy.

Frankel, E.N.; Nash A.M. and Snyder, J.M. 1987. A methodology study to evaluate quality of soybeans stored at different moisture levels. J. Am. Oil Chem. Soc., $74: 387$ - 391.
Gross, J.L.; Zelmanvutz-Moulin, C.C.; Mello, D.F.; Perasssolo, V.; Leitao, M.; Hoefel, A., Paggi, A. and Azevedo, M.H. 2002.Effect of a chicken - based diet on renal function and lipid profile in patients with type 2 diabetes. D. Care., 25: $645-651$.

Hassanin-Fatin, S. and Hassan, M.A. 2003. Chemical indices of incipient deterioration in chicken cut-up products. Benha. V.M.J., 14(2):54-65.

Ke, P.J. and Woyewoda, A.D. 1978.Tritimetric method for and determination of free fatty acids in tissues and lipids with ternary solvents $m$-cresol purple indicator.Anal. Chem. Acta., 99:387-391.

Kumar, N. and Singnal, O.P. 1991. Cholesterol oxides and atherosclerosis: A review. J. Sci Food Agric., 55:497 510.

Liu, X.D.; Jayasena, D.D.; Jung, Y.; Jung, S.; Kang, B.S.; Heo, K.N.; Lee, J.H.; and Jo, C. 2012. Differential proteome analysis of breast and thigh muscles between koeran native chickens and commercial broilers. Asian Australas. J. Anim. Sci., 25:895-902.

Masoud, R.M.; Fakhreddin, H.S.; Ershad, L.H. and Safari, R. 2008. Effect of delayed icing on quality changes of iced rainbow trout (Onchorychusmykiss). Food Chemistry, 106:161 -165.

Melton, S.L. 1983.Methodlogy for lipid oxidation muscle foods. Food Technol., 37(7): 105-116.

Pearson, D. 1984.Chemical analysis of foods $8^{\text {th }}$ Ed, publishing Co., Churchill Livingston, Edinburgh, London, UK.

Pikul, J.; Leszezynski, D.E. and Kummerow, F. 1989. Evaluation of three modified TBA methods for measuring lipid oxidation in chicken meat. J. Agri. Food Chem., 37:1309. 
Raharjo.S. and Sofos, J.N. 1993. Methodology for measuring malonaldehyde as a product of lipid peroxidation in muscle tissues: a review. Meat Science, 35: 145-169.

Saad, M.S.; Ibraheem, H.M.; Hassam, M.A. and Hassan, F.Y. 2013a. Fractionation of amino acids of frozen poultry meat. Benha Veterinary Medical Journal, 24(1):86-91.
Saad, M.S.; Ibraheem, H.M.; Hassam, M.A. and Hassan, F.Y. 2013b. Fractionation of amino acids of frozen poultry meat. Benha Veterinary Medical Journal, 24(1):92-97.

Shedeed, N.A. 1999.Evaluation of microwave cooking of chicken meat.M.Sc. thesis Fac., of Agric., Cairo Univ Egypt.

Vogel, S.F. 1975.Fatty acid composition of raw and processed meats. Food Technol., 29: 147-152. 